\title{
Endoscopic Dilation of Pharyngoesophageal Strictures: There Are More Dimensions than a Diameter
}

\author{
Diana Martins $^{a}$ Sara Pires ${ }^{b}$ Pedro Pimentel-Nunes ${ }^{c-e}$ Rui Almeida Silva ${ }^{c}$ \\ Claúdia Camila Dias ${ }^{d, f}$ Mário Dinis-Ribeiro ${ }^{c-e}$
}

\begin{abstract}
${ }^{a}$ Gastroenterology Department, Tondela-Viseu Hospital Center, Viseu, Portugal; ${ }^{b}$ Gastroenterology Department, Espirito Santo Hospital, Évora, Portugal; ' Gastroenterology Department, Portuguese Oncology Institute of Porto, Porto, Portugal; ${ }^{d}$ CINTESIS - Center for Health Technology and Services Research, Porto, Portugal; ${ }^{e}$ CIDES-FMUP Faculty of Medicine of the University of Porto, Porto, Portugal; fDepartment of Community Medicine, Information and Decision in Health, Faculty of Medicine of the University of Porto, Porto, Portugal
\end{abstract}

\section{Keywords}

Benign esophageal strictures · Endoscopy · Dilation ·

Personal satisfaction - Treatment outcome

\section{Abstract}

Background/Aims: Dysphagia due to benign pharyngoesophageal strictures (PES) often requires repeated dilations; however, a uniform definition for the therapeutic efficacy of this technique has not been yet established. We aimed to assess the overall efficacy of endoscopic dilation of pharyngoesophageal anastomotic or post-radiotherapy (post-RT) strictures. Methods: The data of 48 patients with post-RT $(n=29)$ or anastomotic PES $(n=19)$ submitted to endoscopic dilation during a 3-year period were retrospectively assessed. The Kochman criteria were used to determine refractoriness and recurrence. Patients were asked to answer a questionnaire determining prospectively the dilation program efficacy as (a) dysphagia improvement, (b) dysphagia resolution, (c) need for further dilations, or (d) percutaneous endoscopic gastrostomy (PEG) during the previous 6 months. Need for additional therapy was considered an inefficacy criterion. Results: The median number of dilations per patient was 4 (total of 296 dilations) with a median follow-up of 29 months. The mean predilation dysphagia Mel-

\section{KARGER}

E-Mail karger@karger.com www.karger.com/pjg
(C) 2018 Sociedade Portuguesa de Gastrenterologia Published by S. Karger AG, Basel

Karcer

Open access

This article is licensed under the Creative Commons AttributionNonCommercial-NoDerivatives 4.0 International License (CC BYNC-ND) (http://www.karger.com/Services/OpenAccessLicense) Usage and distribution for commercial purposes as well as any distribution of modified material requires written permission.
low-Pinkas score was 3 and the initial stenosis diameter was $7 \mathrm{~mm}$. Fifteen and $29 \%$ of patients presented with the Kochman criteria for refractory and recurrent strictures, respectively. Moreover, 96 and $60 \%$ showed dysphagia improvement and resolution, respectively. Seventy-five-percent did not require dilations during 6 months, and $89 \%$ did not require PEG. From the patients' perspective, overall efficacy was achieved in $58 \%$ of cases. Nine additional therapies were required. Number of dilations (OR 0.7), stricture diameter (OR 2.2), and nonrecurrence criteria (OR 14.2) appeared as significant predictors of overall efficacy, whereas refractory stenosis criteria did not. Conclusions: Endoscopic dilation seems to be effective for patients with dysphagia after RT or surgery, especially when assessed as patient perception of improvement. Narrow strictures, recurrent ones, and strictures requiring a higher number of dilations may predict worse outcomes. Key Message: Health professionals should establish well-defined efficacy criteria for dilations and base their decision beyond exclusively objective measurements.

(C) 2018 Sociedade Portuguesa de Gastrenterologia Published by S. Karger AG, Basel

The work was carried out at the Gastroenterology Department, Portuguese Oncology Institute of Porto.
Dr. Diana Martins

Gastroenterology Department, Tondela-Viseu Hospital Center

Avenida Rei Dom Duarte

PT-3504-509 Viseu (Portugal)

E-Mail dianacpmartins@gmail.com 


\section{Dilatação Endoscópica de Estenoses Faringo- Esofágicas: Mais Dimensões do que Diâmetros}

\section{Palavras Chave}

Estenoses esofágicas benignas · Endoscopia · Dilatação .

Satisfação pessoal $\cdot$ Resultado do tratamento

\section{Resumo}

Introdução e objetivo: A disfagia devido a estenoses faringo-esofágicas benignas requer frequentemente dilatações repetidas, não existindo, contudo, uma definição estabelecida para a eficácia desta terapêutica. Pretendemos avaliar a eficácia-global de dilatações endoscópicas de estenoses rádicas e anastomóticas faringo-esofágicas. Métodos: 48 doentes com estenoses pós-radioterapia $(n=29)$ e estenoses anastomóticas $(n=19)$ submetidos a dilatação endoscópica durante um período de 3 anos foram avaliados retrospetivamente. Os critérios de Kochman foram utilizados para determinar refratariedade e recorrência. Os doentes foram convidados a responder um questionário determinando prospectivamente a eficácia-global das dilatações como (a) melhoria da disfagia ou (b) resolução, (c) ausência de dilatação adicional durante 6 meses e (d) ausência de PEG para alimentação. A necessidade de terapêutica adicional foi considerada um critério de ineficácia. Resultados: A mediana do número de dilatações por doente foi de 4 (total de 296 dilatações) durante um followup médio de 29 meses. O grau de disfagia (Mellow-Pinkas score) médio pré-dilatação foi 3 e o diâmetro inicial médio da estenose foi $7 \mathrm{~mm}$. Quinze e $29 \%$ apresentaram critérios para estenoses refratárias e recorrentes, respetivamente. Ademais, (a) $96 \%$ dos pacientes apresentaram melhoria da disfagia, (b) $60 \%$ resolução, (c) $75 \%$ não exigiram dilatação durante 6 meses e (d) $89 \%$ não necessitaram de PEG. Em suma, 58\% apresentaram critérios de eficácia-global. Foram necessárias nove terapêuticas adicionais. O número de dilatações (OR 0.7), o diâmetro da estenose (OR 2.2) e a ausência de critérios de recorrência (OR 14.2) apareceram como preditores significativos de eficácia global, mas as estenoses refratárias não. Conclusões: A dilatação endoscópica parece eficaz para estenoses pós-radioterapia ou cirurgia, especialmente quando avaliada subjetivamente. Estenoses estreitas, recorrentes e que requerem maior número de dilatações parecem prever piores outcomes. Mensagem-chave: Os profissionais de saúde devem estabelecer critérios de eficácia bem definidos para as dilatações, não devendo basear a sua decisão apenas em medidas objetivas.

๑ 2018 Sociedade Portuguesa de Gastrenterologia Published by S. Karger AG, Basel
GE Port J Gastroenterol 2018;25:291-298 DOI: $10.1159 / 000486608$

\section{Introduction}

Benign pharyngoesophageal strictures (PES) may affect $3-7 \%$ of patients submitted to head and neck as well as esophageal cancer therapy [1-3]. PES often lead to dysphagia, causing a great impact on patients' quality of life [4].

Although technically challenging, the cornerstone of the management of benign PES is still dilation therapy with bougie dilators or balloons $[5,6]$. When treating these patients, it is important to be aware of the fact that the ultimate goal of therapy is to return patients to an oral diet and to permit gastrostomy tube removal while avoiding adverse events which, although rare (polled complication rate of $4 \%$ per patient [7]), may include perforation, bleeding, and bacteremia [8-10].

Many studies have described the efficacy of endoscopic dilations in benign PES. However, there is no solid definition of therapeutic efficacy, and this concept frequently emphasizes technical aspects. There are two types of success dimensions addressed in the current literature: technical success and clinical success.

The first definition concerns the ability of the endoscopist to traverse the stricture with the chosen dilator [11] and subsequent completion of dilation effectively increasing the luminal diameter (usually by $3 \mathrm{~mm}[12,13]$ and seldom by $\geq 5 \mathrm{~mm}$ [14]). Occasionally this definition includes a target diameter of 14-15 mm [14-16]. Kochman et al. [17] also proposed a technical definition of refractory and recurrent stricture: if a stricture cannot be successfully remediated to a dilation diameter of $14 \mathrm{~mm}$ over 5 sessions at 2 -week intervals, it should be defined as refractory; if one cannot maintain a satisfactory luminal diameter for 4 weeks once $14 \mathrm{~mm}$ have been achieved, it is considered recurrent. These definitions have been accepted and used in the literature, establishing a subgroup of challenging strictures for which an alternative approach may be required.

The definition of clinical success is less consistent. Most authors defined clinical success as resolution of dysphagia (or tolerance of soft diet) measured by different scores $[2,12,14-16,18,19]$, often requiring a variable dilation-free period $[11,13,18,20,21]$ and considering percutaneous endoscopic gastrostomy (PEG) status [20, 22,23 ]. Francis et al. [22] also reported patient satisfaction with the dilation program.

Despite the variable concept of efficacy, it is known that the majority of patients with benign strictures will be effectively treated with up to five dilations [15], but about one-third of patients will develop recurrent dysphagia af- 
ter dilation within the first year, and $10 \%$ of patients will need ongoing dilations to become dilation free $[14,16$, 18]. On the other hand, only 1 out of 3 refractory benign strictures will achieve clinical resolution defined as no need for endoscopic dilation, surgery, or PEG for a 6-month period [20].

The aim of our study was to assess the overall longterm efficacy of an endoscopic dilation program in postradiotherapy (post-RT) and anastomotic PES, considering also the patients' perspective and the potential predictive factors for dilation efficacy.

\section{Methods}

\section{Type of Study and Selection of Patients}

This study was carried out at a tertiary oncology center. We retrospectively examined the data of consecutive patients who underwent pharyngoesophageal endoscopic dilation for benign PES from January 2013 to December 2015. The inclusion criteria were patients aged $>18$ years, histologically confirmed diagnosis of benign esophageal stricture, patients under a dilation program, and a minimum follow-up of 12 months. The exclusion criteria were benign strictures of other etiology than post-RT therapy or postanastomotic strictures. A prospective telephonic interview was performed to assess the overall efficacy of the endoscopic dilation program.

\section{Endoscopic Procedure and Dilation Program}

Endoscopic dilations were performed as outpatient procedures. The dilation technique used was determined by the operator, the stricture complexity, and the availability of fluoroscopic control. Patients with partial stenosis underwent anterograde dilation. If the patient had a complete stenosis, i.e., a guidewire was unable to be passed through the residual lumen or a residual lumen was not visualized either via endoscope or fluoroscopy, retrograde dilation (similarly to the one previously described by Lew et al. [24]) or anterograde-retrograde rendezvous technique [25] were performed.

Endoscopic balloon or bougie dilation were performed according to standard clinical practice with the patient under deep sedation. Dilation was preferentially performed with Savary-Gilliard polyvinyl dilators (Wilson-Cook Medical, Winston-Salem, NC, USA) over a spring-tip stainless steel guidewire that was advanced through the gastroscope under fluoroscopy to the stomach. Bougies of increasing size were passed over the guidewire. Depending on the tightness of the stricture, dilators were passed during each session, usually according to the rule of three. Through-the-scope balloon dilators (controlled radial expansion wire-guided dilation balloon, Boston Scientific) were used when fluoroscopy was not available or if it was the operator's choice (in general after failure of previous dilator procedure); these dilations were carried out under wire guidance as well. Dilation sessions were rescheduled based on endoscopic findings and dysphagia severity, which was measured with the five-scaled Mellow-Pinkas score [26] before each procedure. Dilation sessions were suspended in case of technical failure and were not rescheduled if the stricture was remedi- ated to a diameter of $12-14 \mathrm{~mm}$ and/or if dysphagia resolution (defined by grade $0-1$ ) was achieved.

\section{Outcomes}

The primary endpoint consisted in determining overall efficacy - assessed by a telephonic interview prospectively done after 12 months of follow-up - as (a) dysphagia improvement, (b) dysphagia resolution (grade 0 or 1 on the Mellow-Pinkas scale), (c) absence of further dilations, or (d) absence of gastrostomy feeding during the previous 6 months. A patient was considered to present overall efficacy if his dysphagia had (a) improved or (b) resolved with treatment and if (c) he had not needed more dilations and also if (d) he had not needed to be fed by gastrostomy during the previous 6-month period. Need for additional therapy such as stent or PEG placement, incisional therapy, corticosteroids injection, or surgery was considered as a criterion of inefficacy. The secondary endpoints were technical success, defined as the ability to traverse the stricture with the chosen dilator and subsequent completion of dilation (increasing the luminal diameter by at least $3 \mathrm{~mm}$ ), PEG removal rate during dilations, frequency of recurrent and refractory PES defined based on the Kochman criteria [17], and predictive factors for overall efficacy.

\section{Collected Data}

The baseline patient, stricture, and dilation technique characteristics were recorded and included age, sex, cancer location, cancer therapy (surgery, RT, chemotherapy), type of stricture (classified as post-RT or postsurgery according to the endoscopist's impression and previous therapy), location (proximal or distal), stenosis size (based on the diameter of the adult upper endoscope, Olympus Corporation), minimum and maximum diameter dilation, intra- and postprocedural adverse events (bleeding, aspiration, deep laceration requiring antibiotics, perforation, fistula, death), overall deaths, number of dilations, and time intervals between dilations.

\section{Predictive Variables and Statistical Analysis}

Results were either expressed as medians with interquartile ranges if data did not follow normal distribution or as means with standard deviations if data were normally distributed. Potential predictive factors for the dilation program's overall efficacy were assessed by logistic regression; uni- and multivariate analysis were performed. A significance level of 0.05 was considered to have statistical value. Stricture etiology, previous RT and surgery, initial dysphagia score, initial stricture diameter, number of dilations, maximum first dilation diameter, as well as recurrent and refractory stricture status were evaluated as predictive values.

Data analysis was performed using Statistical Package for the Social Sciences (SPSS), version 22.

\section{Results}

\section{Patients, Strictures, and Dilation Technique Characteristics}

Fifty-one patients met inclusion criteria; 3 of them were excluded because they presented other benign strictures etiologies. Forty-eight patients proceeded to the 
Table 1. Patient, stricture, and dilation technique characteristics

\begin{tabular}{|c|c|c|c|c|}
\hline & $\begin{array}{l}\text { Overall } \\
(n=48)\end{array}$ & $\begin{array}{l}\text { Post RT } \\
(n=29,60.4 \%)\end{array}$ & $\begin{array}{l}\text { Post surgery } \\
(n=19,39.6 \%)\end{array}$ & $p$ \\
\hline \multicolumn{5}{|l|}{ Patient characteristics } \\
\hline Male sex & $41(85.4 \%)$ & $25(86.2 \%)$ & $16(84.2 \%)$ & ns \\
\hline Age, years & $66(12)$ & $63(12)$ & $61(17)$ & ns \\
\hline \multicolumn{5}{|l|}{ Location of previous neoplasia } \\
\hline Pharynx and larynx & $22(45.8 \%)$ & $22(75.8 \%)$ & $0(0 \%)$ & $<0.001$ \\
\hline Esophagus & $19(39.6 \%)$ & $6(20.7 \%)$ & $13(68.4 \%)$ & 0.001 \\
\hline Stomach & $4(8.3 \%)$ & - & - & - \\
\hline Other & $3(6.3 \%)$ & - & - & - \\
\hline Surgery & $39(81.3 \%)$ & $22(75.9 \%)$ & $17(89.5 \%)$ & ns \\
\hline $\mathrm{RT}$ & $38(79.2 \%)$ & $29(100 \%)$ & $9(47.4 \%)$ & $<0.001$ \\
\hline $\mathrm{RT}+$ surgery & $30(62.5 \%)$ & $22(75.9 \%)$ & $9(47.4 \%)$ & 0.046 \\
\hline Initial dysphagia & $3(3-4)$ & $3(3-4)$ & $3(3-4)$ & ns \\
\hline PEG previous to dilation therapy & $21(43.8 \%)$ & $13(48.1 \%)$ & $8(47.1 \%)$ & ns \\
\hline \multicolumn{5}{|l|}{ Stricture characteristics } \\
\hline Proximal location & $43(89.6 \%)$ & $26(89.7 \%)$ & $17(89.5 \%)$ & ns \\
\hline Median initial lumen caliber, $\mathrm{mm}$ & $7(5-8)$ & $8(5-10)$ & $6(5-10)$ & ns \\
\hline \multicolumn{5}{|l|}{ Dilation technique characteristics } \\
\hline \multicolumn{5}{|l|}{ Technique } \\
\hline Savary bougies & $284(96 \%)$ & & & \\
\hline Through-the-scope balloon & $12(4 \%)$ & & & \\
\hline Number of dilations & $4(2-9)$ & $4(2-9)$ & $3(1-8)$ & ns \\
\hline Dilations time interval, weeks & $5(3-6)$ & $4(3-6)$ & $5(3-6)$ & ns \\
\hline \multicolumn{5}{|l|}{ First dilation } \\
\hline Minimum diameter, $\mathrm{mm}$ & $9(7-11)$ & $10(9-11)$ & $9(7-11)$ & ns \\
\hline Maximum diameter, $\mathrm{mm}$ & $13(11-15)$ & $13(11-15)$ & $13(11-15)$ & ns \\
\hline
\end{tabular}

Values are presented as $n(\%)$, mean (standard deviation), or median (interquartile range). ns, not significant; PEG, percutaneous endoscopic gastrostomy; RT, radiotherapy.

study and underwent a total of 296 dilations for remediation, with a median of 4 (2-9) dilations per patient performed with a median interval of 5 (3-6) weeks. Patient, stricture, and dilation technique characteristics are shown in Table 1. Eighty-five percent of patients $(n=41)$ developed their strictures after treatment for pharyngolaryngeal or esophageal cancer; the other patients received treatment for brain, thyroid, lymphoma, and gastric cancer. Around $80 \%(n=39)$ of all patients were submitted to RT and the same percentage $(n=38)$ to surgery; $62 \%$ $(n=30)$ were submitted to both treatments. Sixty percent $(n=29)$ and $40 \%(n=19)$ of patients belong to the postRT and anastomotic strictures group, respectively, and these two groups presented similar characteristics. Predilation dysphagia Mellow-Pinkas score and luminal caliber were $3 \pm 1$ and $7 \pm 2.8 \mathrm{~mm}$, respectively. The preferential dilation technique consisted in Savary bougies dilation (96\%) done via traditional anterograde access (99\%).
Three of 296 dilations (1\%) were performed by the retrograde or the anterograde-retrograde rendezvous technique.

\section{Efficacy}

As regards overall long-term efficacy, 28 of 30 illegible patients (93\%) answered the interview: $96 \%$ had improved, $60 \%$ had no dysphagia (grade $0-1$ ), $75 \%$ had not needed further dilations, and $89 \%$ had not needed PEG for feeding in the previous 6-month period, with an overall efficacy of $58 \%$ (Fig. 1). The median final dysphagia score was $1(0-2)$. Nine additional therapies were required (6 PEGs, 2 stents, 1 incisional therapy). Fifteen percent $(n=7)$ and $29 \%(n=14)$ presented criteria of refractory and recurrent PES, respectively. Overall, 17 (from 21 patients with a PEG previous to dilation therapy) were able to resume feeding per os (81\%). Technical efficacy was achieved in $88 \%$ of dilations $(n=260)$. Ten 
Fig. 1. Efficacy-defining criteria and overall efficacy of the endoscopic dilation program (expressed in \%). * Twenty-one of 36 patients (28 interview responders plus 8 presenting inefficacy criteria due to additional therapy) presented overall efficacy criteria.

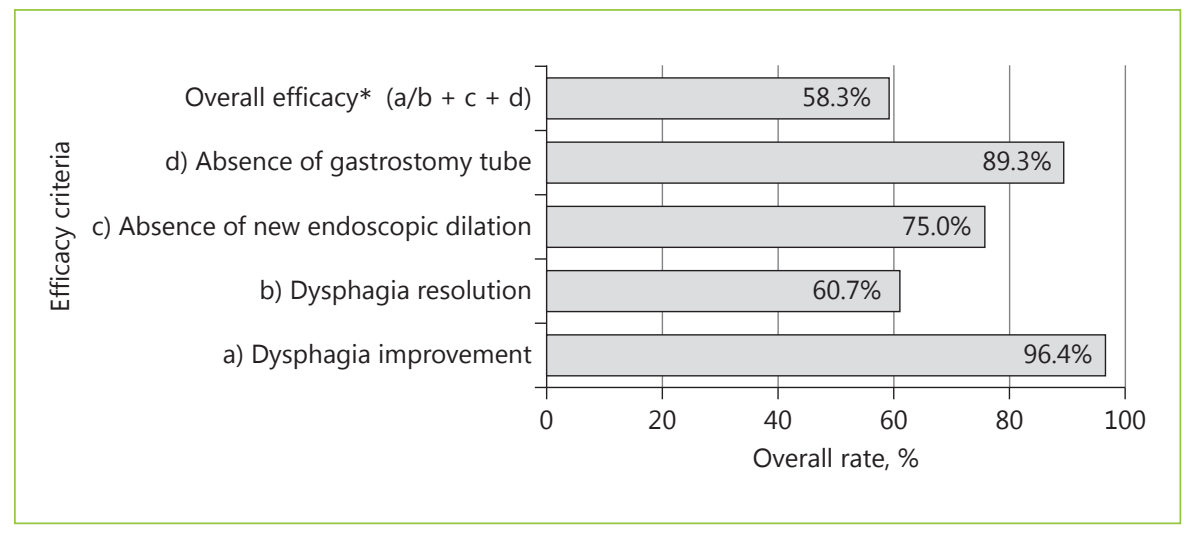

patients (4 with a PEG previous to dilations and 6 who needed additional gastrostomy for feeding) had a PEG (21\%) at the end of follow-up. The main outcomes of this study are shown in Table 2 . All patients presented a minimum follow-up of 12 months, and the overall median follow-up was $29.2 \pm 11.2$ months.

\section{Predictive Factors for Efficacy}

The predictive factors for overall efficacy are shown in Table 3. The initial luminal diameter, the number of dilations, and the absence of recurrent stenosis criteria were significant predictors of overall efficacy on univariate analysis. On multivariate analysis, the only factors that showed a tendency for predicting efficacy were the absence of criteria for recurrent stenosis $(p=0.1)$ and the initial luminal diameter $(p=0.09)$. Etiology and refractoriness of stenosis were not significant predictors of overall efficacy (uni- and multivariate analysis).

\section{Adverse Events}

There were two postprocedure adverse events (0.7\%): one deep laceration and one fistula. Ten patients died during follow-up due to causes not related to the endoscopic procedure.

\section{Discussion}

The management of benign PES, such as post-RT and anastomotic ones, remains challenging and time consuming. Endoscopic dilation still is the standard management of PES [20, 27]; however, there are no established definitions of therapeutic efficacy or predictive factors for nonresponsive PES.

Endoscopic Dilation of

Pharyngoesophageal Strictures
Table 2. Endoscopic dilation program outcomes

\begin{tabular}{ll}
\hline Study outcomes & Frequency, \% $(n)$ \\
\hline Overall efficacy & $58.3 \%(21)$ \\
Technical efficacy & $87.8 \%(260)$ \\
Gastrostomy tube independence & $81.0 \%(17)$ \\
Need for additional therapy & $18.8 \%(9)$ \\
Refractory stenosis & $14.6 \%(7)$ \\
Recurrent stenosis & $29.2 \%(14)$ \\
\hline
\end{tabular}

We aimed to assess the long-term efficacy of endoscopic dilations in post-RT and anastomotic PES. We reviewed a database of almost 300 dilation procedures performed in 48 patients in whom an overall efficacy of about $60 \%$, a perception of dysphagia improvement of $96 \%$, and a gastrostomy tube independence of $>80 \%$ were achieved after a follow-up of $29 \pm 11$ months. We designed our definition of overall efficacy as a trilogy where dysphagia improvement assessed as a "patient-reported outcome" needs to be associated with a 6-month period of absence of further dilations and PEG feeding. These criteria made our efficacy definition more demanding and therefore hard to compare with previously described endoscopic dilation efficacy rates $[2,12,15,16,18,20,23]$. A recent meta-analysis [7] reported an estimated overall clinical success rate per patient (with a post-chemotherapy and RT or RT alone stricture) of 72.9\% (95\% CI 65.7-80.1\%), with data suffering from significant heterogeneity as success was defined by resolution or improvement of different dysphagia scales. Previous findings stated that a soft/ normal diet may be achieved in $>70 \%[12,16,23,28]$ compared to $60 \%$ reported in our cohort. On the other hand, our dysphagia improvement perception rate was 
Table 3. Predictive factors for overall efficacy

\begin{tabular}{|c|c|c|c|c|}
\hline Stricture etiology (post-RT) & $1.692(0.399-7.172)$ & 0.475 & & \\
\hline Initial dysphagia score & $0.621(0.258-1.490)$ & 0.286 & & \\
\hline Initial stricture caliber & $2.228(1.159-4.282)$ & 0.016 & $2.265(0.873-5.875)$ & 0.093 \\
\hline Total number of dilations & $0.732(0.579-0.926)$ & 0.009 & $0.975(0.635-1.495)$ & 0.907 \\
\hline Refractory stricture & $0.941(0.177-4.997)$ & 0.943 & & \\
\hline
\end{tabular}

$\mathrm{RT}$, radiotherapy.

excellent and followed the one previously described by Francis et al. [22]. Moreover, our independence of gastrostomy tube rate was better than in most previous studies $[22,23,28]$.

We found that initial lumen diameter, number of dilations, and nonrecurrent strictures were predictive factors for overall efficacy. The first two factors have previous been described [23]. Our predictive factors for efficacy were only significant in the univariate analysis, which may be explained by the small and complex population analyzed, requiring multiple dilations, more than what was reported in previous similar studies [23]. Only nonrecurrent strictures and the ones with larger luminal diameters showed a tendency for predicting overall effica$c y$, according to our efficacy definition that demanded for a 6-month period without further dilations. Refractory strictures did not present a worse prognosis in this population and therefore may benefit from this endoscopic therapy. We think that our refractory strictures did not predict a worse outcome due to the basal complexity of this group of PES and to the fact that even small dilations may contribute for improving patients' quality of life, for example by allowing patients to swallow liquids and their own saliva, which may be measured by our definition of efficacy as an "improvement" of dysphagia.

Despite several important findings, this study has some limitations that deserve to be mentioned: first, the data were collected retrospectively, leading to missing information; this included information on staging, treatment regimen, strictures characteristics such as additional data regarding stricture complexity, and nutritional response to treatment. Second, due to the unicentric nature of the study, the low incidence of these strictures, and the recent implementation of an electronic registry, the cohort was relatively small, potentially providing inade- quate statistical power to identify important associations and to perform a better multivariate analysis. The validity of this and other associations is uncertain, and future work is required to better understand why these strictures develop and how these high-grade strictures can best be treated.

Our study also presents strengths that deserve to be reported: our dilation program proved to be safe and efficient (with an excellent dysphagia perception amelioration), the overall efficacy of our dilation program highlights patients' individual perception of improvement during therapy, and we present the longest follow-up period described in the literature for combined analysis of anastomotic and post-RT strictures.

Endoscopic dilation will probably persist as the first therapeutic step in this setting, but a consensus on endoscopic dilation efficacy should be established in order to better understand what variables may predict a higher risk of nonresponse. According to current knowledge, if this approach is not sufficient, a next step should be discussed with the patient as few options are available in order to maintain oral feeding: incisional therapy may be tried for anastomotic strictures $[8,29,30]$ or stents may be placed [31-34]. If still recurrent/refractory, self-bougienage can be proposed to selected patients with benign PES $[8,35]$, as it has been proven that this is a very safe and effective therapy $[36,37]$.

In conclusion, our PES endoscopic dilation program presents a good long-term efficacy, with negligible adverse events. Our definition of efficacy adopted objective and subjective (patient perception of improvement) criteria. Narrow strictures, recurrence stenosis, and the need for an increased number of dilations may alert physicians for a potentially more difficult therapeutic approach. Refractory strictures do not present a worse prognosis and 
may benefit from the endoscopic dilation program, which may alert for the potential need for a refractoriness definition revision. Health professionals should establish well-defined efficacy criteria for dilations and should base their decisions beyond exclusively objective dimensions.

\section{Statement of Ethics}

The study protocol was approved by the hospital's ethics commission. Standard informed consent was obtained from patients before each procedure and study.

\section{Disclosure Statement}

The authors have no conflicts of interest to declare.

\section{Author Contributions}

Conception and design: D. Martins, R. Almeida Silva, M. Dinis-Ribeiro. Acquisition, analysis, and interpretation of the data: D. Martins, S. Pires, C. Dias. Drafting of the article: D. Martins, M. Dinis-Ribeiro, P. Pimentel-Nunes. Critical revision of the article for important intellectual content: all authors. Final approval of the article: all authors.

\section{References}

$\checkmark 1$ Nguyen NP, Smith HJ, Moltz CC, et al: Prevalence of pharyngeal and esophageal stenosis following radiation for head and neck cancer. J Otolaryngol Head Neck Surg 2008;37:219224.

2 Tuna Y, Koçak E, Dinçer D, Köklü S: Factors affecting the success of endoscopic bougie dilatation of radiation-induced esophageal stricture. Dig Dis Sci 2012;57:424-428.

-3 Laurell G, Kraepelien T, Mavroidis P, et al: Stricture of the proximal esophagus in head and neck carcinoma patients after radiotherapy. Cancer 2003;97:1693-1700.

4 Williams VA, Watson TJ, Zhovtis S, et al: Endoscopic and symptomatic assessment of anastomotic strictures following esophagectomy and cervical esophagogastrostomy. Surg Endosc 2008;22:1470-1476.

5 Scolapio JS, Pasha TM, Gostout CJ, et al: A randomized prospective study comparing rigid to balloon dilators for benign esophageal strictures and rings. Gastrointest Endosc 1999;50:13-17.

6 Cox JG, Winter RK, Maslin SC, et al: Balloon or bougie for dilatation of benign oesophageal stricture? An interim report of a randomised controlled trial. Gut 1988;29:1741-1747.

7 Moss WJ, Pang J, Orosco RK, et al: Esophageal dilation in head and neck cancer patients: a systematic review and meta-analysis. Laryngoscope 2018;128:111-117.

8 Van Boeckel PG, Siersema PD: Refractory esophageal strictures: what to do when dilation fails. Curr Treat Options Gastroenterol 2015; 13:47-58

$\$ 9$ Lew RJ, Kochman ML: A review of endoscopic methods of esophageal dilation. J Clin Gastroenterol 2002;35:117-126.

10 Poincloux L, Rouquette O, Abergel A: Endoscopic treatment of benign esophageal strictures: a literature review. Expert Rev Gastroenterol Hepatol 2017;11:53-64.
11 Park JH, Kim KY, Song HY, et al: Radiationinduced esophageal strictures treated with fluoroscopic balloon dilation: clinical outcomes and factors influencing recurrence in 62 patients. Acta Radiol 2017, Epub ahead of print.

12 Agarwalla A, Small AJ, Mendelson AH, Scott FI, Kochman ML: Risk of recurrent or refractory strictures and outcome of endoscopic dilation for radiation-induced esophageal strictures. Surg Endosc 2015;29:19031912.

13 Mendelson AH, Small AJ, Agarwalla A, Scott FI, Kochman ML: Esophageal anastomotic strictures: outcomes of endoscopic dilation, risk of recurrence and refractory stenosis, and effect of foreign body removal. Clin Gastroenterol Hepatol 2015;13:263-271.e1.

14 Rodrigues-Pinto E, Pereira P, Ribeiro A, et al: Risk factors associated with refractoriness to esophageal dilatation for benign dysphagia. Eur J Gastroenterol Hepatol 2016;28:684688.

15 Pereira-Lima J: Endoscopic dilation of benign esophageal strictures: report on 1043 procedures. Am J Gastroenterol 1999;94:14971501.

16 Ahlawat SK, Al-Kawas FH: Endoscopic management of upper esophageal strictures after treatment of head and neck malignancy. Gastrointest Endosc 2008;68:19-24.

17 Kochman ML, McClave SA, Boyce HW: The refractory and the recurrent esophageal stricture: a definition. Gastrointest Endosc 2005; 62:474-475.

18 Yoda Y, Yano T, Kaneko K, et al: Endoscopic balloon dilatation for benign fibrotic strictures after curative nonsurgical treatment for esophageal cancer. Surg Endosc 2012;26: 2877-2883.

19 Peng KA, Feinstein AJ, Salinas JB, Chhetri DK: Utility of the transnasal esophagoscope in the management of chemoradiation-induced esophageal stenosis. Ann Otol Rhinol Laryngol 2015;124:221-226.
20 Repici A, Small AJ, Mendelson A, et al: Natural history and management of refractory benign esophageal strictures. Gastrointest Endosc 2016;84:222-228.

21 Dhar A, Close H, Viswanath YK, et al: Biodegradable stent or balloon dilatation for benign oesophageal stricture: pilot randomised controlled trial. World J Gastroenterol 2014;20: 18199-18206.

22 Francis DO, Hall E, Dang JH, Vlacich GR, Netterville JL, Vaezi MF: Outcomes of serial dilation for high-grade radiation-related esophageal strictures in head and neck cancer patients. Laryngoscope 2015;125:856-862.

23 Chapuy CI, Annino DJ, Tishler RB, Haddad RI, Snavely A, Goguen LA: Success of endoscopic pharyngoesophageal dilation after head and neck cancer treatment. Laryngoscope 2013;123:3066-3073.

24 Lew RJ, Shah JN, Chalian A, Weber RS, Williams NN, Kochman ML: Technique of endoscopic retrograde puncture and dilatation of total esophageal stenosis in patients with radiation-induced strictures. Head Neck 2004; 26:179-183.

25 Bertolini R, Meyenberger C, Albrecht F, Sulz MC, Putora PM, Broglie MA, et al: Endoscopic dilation of complete oesophageal obstructions with a combined antegrade-retrograde rendezvous technique. World J Gastroenterol 2016;21:2366-2372.

26 Mellow MH, Pinkas H: Endoscopic laser therapy for malignancies affecting the esophagus and gastroesophageal junction. Arch Intern Med 1985;145:1443-1446.

27 Repici A, Vleggaar FP, Hassan C, et al: Efficacy and safety of biodegradable stents for refractory benign esophageal strictures: the BEST (Biodegradable Esophageal Stent) study. Gastrointest Endosc 2010;72:927-934.

28 Goguen LA, Norris CM, Jaklitsch MT, et al: Combined antegrade and retrograde esophageal dilation for head and neck cancer-related complete esophageal stenosis. Laryngoscope 2010;120:261-266 
29 Hordijk ML, van Hooft JE, Hansen BE, Fockens P, Kuipers EJ: A randomized comparison of electrocautery incision with Savary bougienage for relief of anastomotic gastroesophageal strictures. Gastrointest Endosc 2009;70: 849-855.

- 30 Samanta J, Dhaka N, Sinha SK, Kochhar R: Endoscopic incisional therapy for benign esophageal strictures: technique and results. World J Gastrointest Endosc 2015;7:13181326.

-31 van Hooft JE, van Berge Henegouwen MI, Rauws EA, Bergman JJ, Busch OR, Fockens P: Endoscopic treatment of benign anastomotic esophagogastric strictures with a biodegradable stent. Gastrointest Endosc 2011;73: 1043-1047.

32 Siersema P: Stenting for benign esophageal strictures. Endoscopy 2009;41:363-373.

33 Barthel JS, Kelley ST, Klapman JB: Management of persistent gastroesophageal anastomotic strictures with removable self-expandable polyester silicon-covered (Polyflex) stents: an alternative to serial dilation. Gastrointest Endosc 2008;67:546-552.

4 Dan DT, Gannavarapu B, Lee JG, Chang K, Muthusamy VR: Removable esophageal stents have poor efficacy for the treatment of refractory benign esophageal strictures (RBES). Dis Esophagus 2014;27:511-517.

35 Grobe JL, Kozarek RA, Sanowski RA: Selfbougienage in the treatment of benign esophageal stricture. J Clin Gastroenterol 1984;6: 109-112.

36 Dzeletovic I, Fleischer DE, Crowell MD, et al: Self-dilation as a treatment for resistant, benign esophageal strictures. Dig Dis Sci 2013; 58:3218-3223.

37 Qin Y, Halland M: Esophageal self-dilations as a treatment for refractory benign esophageal strictures. Gastrointest Endosc 2017;85: 869 